\title{
STUDY OF CERVICAL CYTOLOGY IN PAPANICOLAOU SMEAR IN TERTIARY CARE CENTRE
}

\author{
Jayun Manish Joshi' ${ }^{1}$,Munjal Jayeshkumar Pandya², Janki Munjal Pandya33, Pallavi Ashokbhai Patel4, Pratik Shaileshbhai Patel ${ }^{5}$ \\ ${ }^{1}$ Associate Professor, Department of Obstetrics and Gynaecology, AMC MET Medical College, Sheth L.G. Hospital. \\ ${ }^{2}$ Assistant Professor, Department of Obstetrics and Gynaecology, AMC MET Medical College, Sheth L.G. Hospital. \\ ${ }^{3}$ Assistant Professor, Department of Obstetrics and Gynaecology, AMC MET Medical College, Sheth L.G. Hospital. \\ ${ }^{4}$ Second Year Postgraduate Resident, Department of Obstetrics and Gynaecology, AMC MET Medical College, Sheth L.G. Hospital. \\ 5 First Year Postgraduate Resident, Department of Obstetrics and Gynaecology, AMC MET Medical College, Sheth L.G. Hospital.
}

\section{ABSTRACT}

\section{BACKGROUND}

Cervical cancer is the most common cancer in Indian females. Globally, it stands second in female malignancies. Study of cervical cytology by Papanicolaou smear is a modality making earlier diagnosis of pathological cell changes, making it possible to reduce morbidity and mortality associated with cervical cancer.

\section{MATERIALS AND METHODS}

This prospective observational study was conducted during January 2016 to July 2016, reviewing 700 Pap smears of the patient presented at Gynaecology Outpatient Department in a tertiary care centre.

\section{RESULTS}

The Pap smears were examined and cytology was noted according to Bethesda scoring system, 2001. Majority of patients (73\%) had non-specific inflammation. Bacterial vaginosis $(4.1 \%)$ and Trichomoniasis $(1.9 \%)$ were amongst the infections showing reactive changes in the smears. Only 2 smears (0.3\%) showed ASCUS (Atypical squamous cell of undetermined significance). LSIL (Low grade squamous intraepithelial lesion) was found in $0.3 \%$. HSIL (High grade squamous intraepithelial lesion) was found in $0.1 \%$ of the patients. No smear showed changes suggestive of carcinoma.

\section{CONCLUSION}

Cervical cancer is a major global threat, taking a huge toll on females of developing countries. Awareness programmes and regular Pap smear examinations can diminish the health issues pertaining to cervical carcinoma.

\section{KEYWORDS}

Papanicolaou Smear, Cervical Cytology, Reproductive Age Women, Bethesda Scoring System.

HOW TO CITE THIS ARTICLE: Joshi JM, Pandya MJ, Pandya JM, et al. Study of cervical cytology in Papanicolaou smear in tertiary care centre. J. Evolution Med. Dent. Sci. 2017;6(88):6087-6089, DOI: 10.14260/jemds/2017/1322

\section{BACKGROUND}

Globally, cervical cancer has been the second most common cancer affecting women and it stands fifth in all the cancers affecting human race. It is the commonest of all the cancers causing mortality in developing nations. ${ }^{1,2,3}$ It is the most common cancer affecting females in India.

Marriage at an early age increases the risk of cervical carcinoma. Intercourse at an early age also is an independent risk factor. Early marriage usually results in early childbearing, again increasing the tendency to getting malignant changes of cervix. Family planning programs have succeeded in reducing population explosion, yet in our country there are still places where even more than two children with lesser than 2 - 3 years of spacing is a routine for a couple. Usage of barrier contraception do prevent many of the sexually transmitted diseases including infection of HPV

'Financial or Other Competing Interest': None.

Submission 28-09-2017, Peer Review 22-10-2017,

Acceptance 28-10-2017, Published 06-11-2017.

Corresponding Author:

Dr. Munjal Jayeshkumar Pandya,

Flat 602, Sachet Allure,

Opposite Riddhi Siddhi Tower,

Jodhpur, Satellite,

Ahmedabad - 380015,

Gujarat, India.

E-mail: munjal171184@yahoo.co.in

DOI: $10.14260 /$ jemds $/ 2017 / 1322$

\section{(c) $\bigcirc$}

(Human Papilloma Virus), which is a known contributor to cervical carcinoma. Females whose sexual partners do not use barrier contraception are at increased risk of getting affected with cervical malignancy. Multiple sexual partners would raise the vulnerability for the cervical malignant lesions. India tops the list of age standardised incidence amongst all the nations of South Asia. ${ }^{4}$

Pap smear has contributed to drastic reduction in morbidity and mortality related to cervical cancer by earlier detection of reversible changes as well as by early diagnosis of further management of irreversible ones. This cytological examination is one of the simplest tools available to detect one of the most common causes of morbidity and mortality. Globally, the incidence of cervical cancer has decreased to almost half over last three decades due to various cervical screening methods. Pap test was invented by Georgios Papanicolaou in 1940s.

Pap smear can be done either by conventional method or by using preservative. Cells from transformation zone are taken using spatula and are directly examined under microscope in conventional method. While newer method includes usage of preservative for the slide once the cells are spread over it and then examining the slide under microscope. Conventional method was thought to be getting more of confounding factors along with cells from cervix, but both the methods are considered equally reliable for detecting changes in cervical cytology. 
Patients with abnormal Pap smear are subjected to colposcopy or colposcopic guided biopsy accordingly, which adds up to further diagnosis of cervical cell abnormalities making it possible to treat these reversible changes, preventing development of malignancy.

This study focuses on diagnosing abnormality in cervical cytology by using Pap smear test in females of reproductive, perimenopausal and menopausal age groups coming to outpatient department of our institute.

\section{Aims and Objectives}

This Study was done keeping following Points as Aims and Objectives-

- To study cervical cytology and its pattern in patients from reproductive age group, perimenopausal age group and menopausal age group presenting in Gynaec Outpatient Department.

\section{MATERIALS AND METHODS}

This prospective observational study was conducted on patients coming with various gynaecological symptoms from the reproductive age group, perimenopausal and menopausal age groups to outpatient department of our institute, which is a tertiary care centre. There were many of the females who came for Pap smear test due to increased awareness and they were included in our study as well.

The patients were explained about the procedure and importance of the test. They were counselled for further followup visits as per the result. Those patients who had sexual intercourse or usage of vaginal pessary or who underwent per vaginum examination within past seven days were called back after seven days keeping in mind not to have any intervention performed in or through vagina till the samples are taken for Pap test.

The patients were placed in lithotomy position. Cleaning with antiseptic solution was avoided. Labia were separated with left hand. Speculum was introduced to retract posterior vaginal wall and anterior vaginal wall was retracted by anterior vaginal wall retractor. Wooden spatula was used to take cells from squamocolumnar junction by sweeping 3600 . The smear was spread over glass slide. It was dipped in a small container with fixative (95\% ethyl alcohol). The slides were stained and reported for the cytological study according to Bethesda scoring system, 2001.

\section{RESULTS}

This prospective observational study includes data of Pap smear taken from 700 patients during the time period of January 2016 to July 2016. The patients were divided into three major age groups, of which $85.3 \%(n=597)$ belonged to the latter half of reproductive age group (30 - 45 years). The second group was of perimenopausal age (46 - 55 years), contributing to $12.7 \%(n=89)$ of the study population. Only $2 \%(n=14)$ belonged to menopausal age group (Table 1$)$.

Majority of the patients presented with single or more symptoms $(69.9 \%, n=489)$. Only $30.1 \%(n=211)$ patients were asymptomatic. Symptomatic group was divided according to main symptom they had, the most common being white discharge per vaginum $(54.2 \%, \mathrm{n}=379)$ followed by lower abdominal pain $(14.7 \%, n=103)$. Only $1 \%$ patients complained of uterine prolapse and post-menopausal bleeding (Table 2).

The Pap smears were examined and diagnosis were put according to Bethesda scoring system, 2001; 15.3\% ( $n=107)$ showed normal cervical cytology; $5 \%(n=35)$ smears were found to be inadequate. Majority of patients $(73 \%, \mathrm{n}=511)$ had non-specific inflammation. Bacterial vaginosis $(4.1 \%$, $\mathrm{n}=29)$ and Trichomoniasis $(1.9 \%, \mathrm{n}=13)$ were amongst the infections showing reactive changes in the smears. Only 2 smears $(0.3 \%)$ showed ASCUS (Atypical squamous cell of undetermined significance). LSIL (Low grade intraepithelial lesion) was found mainly in reproductive age group women, contributing to $0.3 \%(\mathrm{n}=2)$. HSIL (High grade intraepithelial lesion) was found in 1 smear $(0.1 \%)$, in the patient of menopausal age group. No smear showed changes suggestive of carcinoma (Table 3).

\begin{tabular}{|c|c|c|c|}
\hline Sl. No. & Age (Years) & Number of Patients & Percentage (\%) \\
\hline 1 & $30-45$ & 597 & 85.3 \\
\hline 2 & $46-55$ & 89 & 12.7 \\
\hline 3 & $>56$ & 14 & 2 \\
\hline Total & \multicolumn{3}{|c|}{ Table 1. Age-Wise Distribution of the Cases } \\
\hline \multicolumn{3}{|c}{} \\
\hline
\end{tabular}

\begin{tabular}{|c|c|c|}
\hline Symptoms & $\begin{array}{c}\text { Number of } \\
\text { Patients }\end{array}$ & $\begin{array}{c}\text { Percentage } \\
(\%)\end{array}$ \\
\hline Asymptomatic & 211 & 30.1 \\
\hline White discharge per vaginum & 379 & 54.2 \\
\hline Lower abdominal pain & 103 & 14.7 \\
\hline Uterine prolapse & 4 & 0.6 \\
\hline Post-menopausal bleeding & 3 & 0.4 \\
\hline Total & 700 & 100 \\
\hline \multicolumn{3}{|c|}{ Table 2. Symptomatology of the Cases } \\
\hline
\end{tabular}

\begin{tabular}{|c|c|c|}
\hline Diagnosis & $\begin{array}{c}\text { Number of } \\
\text { Patients }\end{array}$ & $\begin{array}{c}\text { Percentage } \\
\text { (\%) }\end{array}$ \\
\hline Inadequate & 35 & 5 \\
\hline NILM & & \\
\hline Normal & 107 & 15.3 \\
\hline $\begin{array}{c}\text { Non-specific } \\
\text { inflammation }\end{array}$ & 511 & 73 \\
\hline Bacterial vaginosis & 29 & 4.1 \\
\hline Trichomoniasis & 13 & 1.9 \\
\hline ASCUS & 2 & 0.3 \\
\hline LSIL & 2 & 0.3 \\
\hline HSIL & 1 & 0.1 \\
\hline Carcinoma & 0 & 0 \\
\hline Total & 700 & 100 \\
\hline Table 3. Pap Smear Finding according to Bethesda \\
\multicolumn{2}{|c|}{ Classification } \\
\hline
\end{tabular}

NILM: Negative for intraepithelial lesion/malignancy ASCUS: Atypical squamous cell of undetermined significance LSIL: Low grade squamous intraepithelial lesion HSIL: High grade squamous intraepithelial lesion

\section{DISCUSSION}

Pap smear is a screening tool for identifying patients with cervical carcinoma. In this study, $85.3 \%$ patients were of reproductive age group. Only $14.7 \%$ patients belonged to perimenopausal and menopausal age groups. Our centre does not have onco-gynaecology subspecialty, thus the study 
conducted did not show any smear showing changes of carcinoma during the study period.

Pap smear is routinely advised to the females right from the reproductive years; $30.1 \%$ patients had no symptoms and came for routine Pap smear examination. Rest of the patients presented with various symptoms. White discharge per vaginum was the major symptom, contributing to $54.2 \%$ of the study population followed by $14.7 \%$ presented with lower abdominal pain. Both of these groups were associated with pelvic inflammatory disease. There were lesser cases from menopausal age group, thus symptoms of uterine prolapse and post-menopausal bleeding were noted only in $1 \%$ of the total patients studied.

99.3\% patients belonged to Negative for Intraepithelial lesion/ malignancy group comparable to a study by Manjit et al. 5 Other studies conducted by Pudasaini $S$ et al and Bamanikar SA et al showed NILM to be around 87\% - 89\%.6,7 Out of NILM group 73\% showed non-specific inflammation; $15.3 \%$ showed normal cytology; $4.1 \%$ smears showed bacterial vaginosis and $1.9 \%$ had trichomoniasis comparable to a study by Pudasaini $\mathrm{S}$ et $\mathrm{al}^{6} ; 0.3 \%$ cases had smears showing LSIL and only $0.1 \%$ showed changes of HSIL comparable to studies by Hirachand et al, Yeasmin et al and Ranabhat et al.8,9,10

Only $0.3 \%$ smears showed ASCUS, comparable to the study by Manjit et al5; $5 \%$ of the smears were labelled to be inadequate.

\section{CONCLUSION}

Pap smear is an easier modality to study cervical cytology. Regular checkup for Pap smear can contribute to earlier diagnosis of metaplastic and dysplastic changes, which are reversible in their earlier stage. Early diagnosis of malignant changes can facilitate early intervention preventing further spread and increasing chances of survival. Government can employ various programs for increasing awareness and implementing Pap test in developing countries to reduce the individual as well as national burden of morbidity and mortality associated with cervical carcinoma. The quality of life of females will be improved by reducing detecting the earlier cytological changes and treating them in time. In addition, the malignant changes will be diagnosed earlier, making it possible to reduce the morbidity as well. Proper awareness and vigilant cytological examination has brought down mortality by cervical cancer drastically and can further contribute to longevity of life for females in future.

\section{REFERENCES}

[1] Denny L. Cervical cancer: prevention and treatment. Discov Med 2012;14(75):125-31.

[2] Verma K. Early diagnosis of cancer cervixepidemiology and incidence. J Cytol 2001;18:73-89.

[3] Masood S. A plea for a worldwide volunteer cervical cancer education and awareness program. A proposal from the international academy of cytology committee on cancer detection for medically underserved women. Acta Cytol 1999;43(4):539-43.

[4] ICO Information Center on HPV and cancer (Summary report 2014-08-22). Human Papillomavirus and Related Diseases in India. 2014.

[5] Bal MS, Goyal R, Suri AK, et al. Detection of abnormal cervical cytology in Papanicolaou smears. J Cytol 2012;29(1):45-7.

[6] Pudasaini S, Prasad KBR, Rauniyar SK, et al. Cervical pap smear-a prospective study in a tertiary hospital. Journal of Pathology of Nepal 2015;5(10):820-3.

[7] Bamanikar SA, Baravkar DS, Chandanwale SS, et al. Study of cervical pap smears in a tertiary hospital. Indian Medical Gazette 2014:250-4

[8] Hirachand S, Bajracharya J, Pradhanang S, et al. Detection of abnormal cervical cytology in papanicolaou smears in a tertiary care center. J Nepal Med Assoc 2013;52(191):462-5.

[9] Yeasmin S, Begum T, Begum LN, et al. Pap smear study and its utility in cervical cancer screening in a tertiary care hospital in Chittagong, Bangladesh. Chattagram Maa-O-Shishu Hospital Medical College Journal 2014;13(1):17-9.

[10] Ranabhat SK, Shrestha R, Tiwari M. Analysis of abnormal epithelial lesions in cervical pap smears in Mid-Western Nepal. Journal of Pathology of Nepal 2011;1(1):30-3. 